\title{
Introduction to Transforming Energy Systems
}

The Paris Agreement put limiting climate change front and centre for societies, where it remained even amidst the novel coronavirus pandemic. This agreement is an urgent call to action, and transforming energy systems to low-carbon alternatives is one of the most crucial actions in halting climate change. These alternatives are those energy resources, technologies and choices that create an alternative to traditional use of fossil fuels to eliminate their net emissions of carbon dioxide and other greenhouse gases. But changing from the current energy system, based largely on fossil-fuel use that disrupts the Earth's carbon cycle and climate, to low-carbon alternatives is perhaps the most profound challenge that societies face. Current technologies that use fossil fuels make dwellings, commercial buildings and factories so much more productive; transport of people and goods easier; and useful materials more abundant and affordable than a century ago. Fossil fuels do much of the work in modern societies, weaving deeply through the fabric of economic activities and household lives. The challenge is to maintain these benefits while pivoting to alternative low-carbon energy resources, technologies and choices.

The foundational investments in transforming energy are those that create low-carbon alternatives to incumbent technologies. Much as an 'industrial enlightenment' of scientific knowledge and its engineering application enlivened the first and second industrial revolutions and created modern energy systems, the awakening of low-carbon technologies today emerges from investments in knowledge and new capabilities. These foundational investments create quasi-public goods - the knowledge and new capabilities necessary to limit climate change while maintaining modern activities. To the extent they are successful, these upfront public and private investments enable all businesses and households to invest in low-carbon alternatives to current technologies to support their economic and household activities. In advanced industrialized countries, as well as China and Russia, transforming energy would require almost all businesses and households to invest in low-carbon alternatives. It also means energy businesses would need to invest in supplying low-carbon electricity and fuels when and where customers demand. In most developing counties, transforming energy would mean pursuing development 
increasingly through renewable resources and cost-effective low-carbon technologies and building capabilities to adopt them.

This book's perspective on energy system transformations is through the lens of the policy and investment decisions of governments, businesses and households that halting climate change would require, including investments in knowledge and new capabilities. Because of the timescales of transformational change and the immense scale of investment it would require, there is no quick fix for energy, but it can be transformed and decisively so to limit climate change. Encouragingly, awakened variable renewables generation technologies have already begun to make a difference, like low-carbon electricity from solar photovoltaic (PV) panels and wind turbines as well as lithium-ion battery packs and battery electric vehicles (Le Quéré et al., 2019). There are important strides too in improving energy and material efficiencies of existing technologies and recycling materials in products at the end of their lives. These changes reduce emissions now as well as facilitate changes to low-carbon alternatives. It is crucially important to learn from these successes in transforming energy systems, as well as their shortcomings.

But if the societal goals of the 2015 Paris Agreement of the United Nations Framework Convention on Climate Change are to be achieved - to limit global warming to well below $2{ }^{\circ} \mathrm{C}$, with a stretch goal of $1.5^{\circ} \mathrm{C}$, and achieve net zero emissions of carbon dioxide and other greenhouse gas emissions from human activities in the second half of this century - energy transformations would need to accelerate. Their scope too would need to widen to encompass most countries and all energy-related sectors as well as agriculture, forestry and other land-use activities. There is much to do to achieve this long-run goal, yet little consensus in economics on the way forward. There is broad agreement in economics on using emissions pricing to internalize the environmental externalities and government policy support for research and development (R\&D) to compensate for well-evidenced knowledge spillovers from this activity. Their rationales are readily grasped and widely understood, but not yet adequately implemented, especially for emissions pricing. Moreover, there is little agreement in economics on use of other policy instruments, such as market-creating and industry-supporting (industrial) policies, even though they have been widely used in practice to advance energy system transformations. They are misdirected and inefficient policies to some, key parts of the policy mix to others.

\section{THE ECONOMICS OF TRANSFORMING ENERGY SYSTEMS}

A narrowly honed, orthodox framing of the economics problem rests on the social cost of carbon dioxide emissions and governments imposing 
a Pigouvian tax on emissions levied in line with this cost (Pigou, 1932, p. 142). The social cost is the present value of expected future social and economic losses associated with greenhouse gas emissions as best assessed. A root cause of climate change is that societies' energy choices in using fossil fuels have long ignored their consequences for the Earth's carbon cycle and climate. Governments' pricing of emissions in this way, or through equivalent measures, would internalize the environmental externality by requiring businesses and households to consider these environmental costs in their decisions. These decisions include what technological innovations to pursue and what goods and services to provide and purchase in markets. This policy paradigm is typically broadened to include another market failure that could hold back low-carbon technologies. This failure arises from well-evidenced knowledge spillovers from innovations and an inability of businesses to capture sufficient economic benefits from successful innovations.

The standard policy prescription in economics for limiting climate change is thus a Pigouvian tax on carbon dioxide emissions and government support for R\&D activities to reward sufficiently investments in innovation. With these two fixes for two key market failures, competitive businesses would in principle develop and supply and their customers would choose the lower- and low-carbon technologies that are required to limit climate change at least cost. In this economics framing, the dynamic process of technological innovation is directed and motivated by temporary market power and rents arising from newly differentiated products or created cost advantages in production, including any arising from emissions pricing. Such Schumpeterian processesrecurring bouts of creative destruction - create and manage the market rents that provide returns to upfront investments in innovation and market creation for new technologies that survive the test of competitive market selection (Schumpeter, 1942, p. 83). This test can be sufficient to establish the social value of innovations and market creation for low-carbon technologies, but this is not necessarily so.

This crisp policy prescription is sufficient in principle to achieve the Paris goals only if businesses and households have well-founded expectations of facing goal-consistent emissions pricing and there are no other market imperfections impeding the advance of low-carbon alternatives. In policy practice, achieving the levels and scope of emissions pricing deemed an adequate reflection of their social costs or government climate goals has been challenging. The reasons for this policy shortcoming lie more in the realm of incomplete markets, adverse distributional impacts, arbitrary political shifts and potential time inconsistencies in policy implementation than with lack of understanding of its readily grasped implications for economic efficiency. In addition to this policy shortcoming, there are three reasons why Schumpeterian market dynamics are unlikely to provide a sufficient impetus to investments 
in innovation and creation of markets for low-carbon technologies, even with government R\&D support. One is that knowledge spillovers arise not only from R\&D activities but also from deploying and using low-carbon technologies-learning from experience. These knowledge spillovers can arise in manufacturing sectors that produce low-carbon technologies as well as within transforming energy systems. They can also arise among customers of low-carbon technologies; for example, through demonstration effects from early technology adopters.

A second is that some low-carbon technologies benefit from substantial scale economies, especially those that can be mass produced with potential for wide deployment across sectors and countries. Some such scale economies are internal to businesses, such as those that arise from larger-scale manufacturing plants. For them, firms could reasonably be expected to earn returns on upfront investments in market creation to achieve them, assuming they face few capital market imperfections. But some scale economies are external to businesses, as suggested by geographical clustering of manufacturing innovation-intensive technologies, including low-carbon ones. Perhaps more significantly, there are also network effects and external scale economies in transforming energy systems, with investments by early adopters of low-carbon technologies contributing to lower costs for those that follow. These effects, for example, can arise from shared infrastructures supporting low-carbon technologies. Cost complementarities among low-carbon technologies that work together to lower overall energy system costs can also create profit spillovers among businesses and customers, which are not necessarily fully internalized in individual decisions. While business models and commercial relationships among firms could be expected to evolve and internalize at least some of these spillovers over time, they are neither immediate nor perfect market mechanisms.

A third reason why Schumpeterian market dynamics are likely to fall short in transforming energy is that at its centre are government-designed and government-regulated markets for electric power. Ubiquitous solar irradiance and wind resources are available at sufficient scale to substitute substantially for fossil-fuel resources, and they are most readily converted into electric power, increasingly cost effectively. But wholesale power markets are inherently imperfect, with their government design balancing efficient scarcity pricing to remunerate fixed investments against potential abuses of market power when markets are tight. The assumption that these government-designed and government-regulated power markets would alone reward large upfront investments in developing and deploying renewable generation and complementary flexibility technologies glosses over missing-market and time-inconsistency problems. For example, governments have an incentive to encourage such sunk investments, but not necessarily to reward them through adequate scarcity and emissions pricing once made. Such time-inconsistency problems are 
a long-standing feature of power markets - they are not confined to emissions pricing. Key policy interventions in transforming electricity systems address this issue through commitment devices, such as long-term investment contracts for renewables generation that benefit from government support.

Narrowly cast structural reforms that ignore potentially relevant market imperfections and the institutional, political and societal contexts in which they take place could reasonably be expected to disappoint. This policy lesson has been hard-learned from other structural reform experiences-be they in financial sectors or economy-wide in the post-communist transitions of Eastern Europe. Well-designed policies to transform energy systems need to consider carefully the inherently imperfect contexts in which they are implemented. To this end, this book examines now-substantial evidence on energy system transformations that have been underway for several decades, especially in the electric power and automobile sectors. It focuses on not only emissions pricing but also non-price policy interventions such as market-creating and industry-supporting (industrial) policies for low-carbon technologies, especially during their early deployment in initial markets. Adapting energy market institutions-government-designed energy markets, their regulations and infrastructures - to low-carbon alternatives is also necessary and given close consideration. As are regulations and standards for energy and material efficiencies, together with evidence on market imperfections and behavioural 'anomalies' that would warrant such policies.

\section{ENERGY-REFORM INTERESTS AND STRATEGIES}

In economics, the optimal goal for the climate is its stabilization by balancing the marginal social benefits of avoiding expected losses from further climate change and the marginal social costs of sooner and deeper emissions cuts. The social cost of carbon dioxide emissions is the emissions price that balances these marginal social benefits and costs. A narrow market-based reform strategy that in principle could support this outcome is straightforward. Fix the two market failures to enable markets to address the fundamental knowledge and environmental problems, then allow competitive market dynamics to determine the optimal extent of climate change. In this perspective, the eventual climate outcome would be determined by the pace and extent of innovation, supported by government R\&D incentives, and investment responses to current and expected emissions prices that reflect the social cost of carbon dioxide emissions. However, this social cost is inherently and highly uncertain, subject to value judgements about potential climate impacts on vulnerable groups and across generations, and can be expected to change over time with advances in climate science and low-carbon technologies. Moreover, its imposition through emissions pricing is vulnerable to adverse distributional impacts, 
shifts in political sentiments and potential time inconsistencies in government policy making, especially in early stages of change. With few opportunities for private investors to manage long-run emission-price risks-for example, because markets for future emissions prices are missing - investment horizons could shorten and backload responses.

Missing from the parsimonious policy mix are thus overcoming missing markets for emission prices and strengthening government commitment devices, as well as addressing other market imperfections that impede development and early deployment of low-carbon technologies. Climate-change outcomes from incomplete policy frameworks would be expected to fall short of what could be reasonably considered optimal. That said, caution in economics about broadening policy prescriptions arises from inconclusive theoretical insights when there are multiple market failures, evidence deemed to be weak on their significance and concern about potential government policy failures in addressing them.

Climate science provides an alternative framing of the societal goal, which is avoiding climate changes to which societies and ecosystems would struggle to adapt. The Paris Agreement interpreted this goal as keeping the likely rise in average surface temperatures this century to well below $2{ }^{\circ} \mathrm{C}$, and making efforts to limit this change to no more than $1.5^{\circ} \mathrm{C}$. The emissions corollary of this goal to limit global warming is to achieve net zero emissions of carbon dioxide and other greenhouse gases from human activities in the second half of this century. Limiting the likely temperature change to $1.5^{\circ} \mathrm{C}$ would require achieving net zero emissions by around mid-century, and a number of countries have already set such goals by 2060,2050 or indeed sooner. Their rationales are rooted more firmly in climate science than still-contentious economics of social benefits and costs. Although, to the extent that it could be reasonably assessed, the optimality of these emissions goals is subject to the same inherent uncertainties and challenges as the social cost of carbon dioxide emissions and its primary implementation through emissions pricing.

The challenge is to create energy-reform strategies that manage effectively these inherent uncertainties, market imperfections and distributional impacts, with the climate-science-framing offering some advantages. The long-run energy system implications of such climate stabilization and quantitative emissions goals are clear. They are time-bound system transformations to net zero emissions of carbon dioxide from traditional use of fossil fuels and industrial processes to halt their contribution to climate change. They create a clear focal point for businesses and their long-run expectations and investment decisions - they need to invest in advancing and deploying low-carbon alternatives. In contrast, an emissions price and its expected pathway over time can direct the focus of governments and businesses more towards short-run 
emissions cuts than long-run system transformations. This reflects in part high uncertainty around long-run emissions prices.

To the extent they are credible, these quantitative climate goals are comparable to large, expected fossil-fuel price shocks, without their adverse short-run impacts on economic activity and income distributions. Much as previous oil price shocks and energy security concerns spurred innovations in renewable technologies, alternative-drivetrain vehicles and energy efficiencies, net zero emissions goals can strengthen incentives for private investments in innovation and market creation for low-carbon alternatives. But on their own these policy goals may only send a relatively weak long-run price signal for want of credibility from implementing policies.

A heterodox domestic energy-reform strategy can help build such credibility - arguably more so than a narrowly honed orthodox economic policy prescription. The latter approach assumes that the Schumpeterian engine fires on all cylinders in all aspects of energy systems. But the approach could disappoint if this engine sputters; for example, in the electricity sector which would likely form the new core of low-carbon energy systems. If emissions pricing and R\&D supports alone had formed the policy mix so far, there would have been the risk of slower advances in new renewable generation and other low-carbon technologies. This outcome, in turn, would have weakened the credibility of reforms, further dulling incentives to develop and deploy alternative technologies. An alternative heterodox policy mix, which has been pursued by most countries initiating low-carbon technology disruptions, includes market-creating and industry-supporting (industrial) policies for low-carbon technologies. These countries tend to be those that specialize in innovation and manufacturing low-carbon technologies, and these policies largely aim to subsidize capital and/or operating costs of relatively expensive investments by early adopters of low-carbon alternatives. These heterodox policies hold the potential to be more self-reinforcing of climate goals, including through sequencing of such industrial policies and emissions pricing.

Industrial policies can overcome at early stages of system transformations missing markets for future emission prices, serve as government commitment devices and build support for sustained energy reforms. By directly creating low-carbon technology demands, especially in countries that specialize in innovations and manufacturing low-carbon technologies, such as China, Germany, Japan, South Korea and United States, these policies direct and support upfront investments by firms in knowledge, innovation and market creation for these technologies. Through home-market effects on production of domestic demands, they foster growing activities and economic interests that benefit from low-carbon technologies and help build policy credibility. These emerging economic interests can help to sustain reforms and the advance of low-carbon alternatives. To the extent they are effective and successful, these 
policies expand economic interests in low-carbon alternatives that can promote stronger reforms over time, including any subsequent ratcheting up of emissions pricing. These industrial policies can also address knowledge spillovers beyond those from R\&D and compensate for cost spillovers from external scale economies and network effects. However, these policies also carry policy failure risks, such as creating market inefficiencies and directing innovations and market creation away from those that would have been pursued in notionally perfect markets. The risks of such policy failures must be balanced against the risks of reform strategies being too narrowly cast and becoming stuck at low levels of climate ambition.

Comprehensive and coherent reform strategies are necessary not only to create self-reinforcing interests in energy transformations, but also to manage policy costs and distributional impacts. Scope for reform strategies to manage policy costs arises from cost spillovers not internalized by firm strategies, market prices or other policies. For example, industrial policy supports for alternative-drivetrain vehicles advanced initial development and deployment of lithium-ion battery packs in the transport sector, for which oil products have high unit energy costs. As battery pack costs decline, this technology is increasingly spilling over to the electric power sector, for which coal and natural gas have low unit energy costs. This targeted and sequenced approach saves real resource costs in advancing low-carbon alternatives. The burden on industrial policies is also eased in those sectors with significant potential for product differentiation and willingness to pay for low-carbon technologies by early adopters, as in automobile markets.

In a heterodox energy-reform strategy with a goal of a time-bound commitment to net zero emissions, emissions pricing complements an early focus on market creation and industry support in three important ways. Firstly, cost-effective, target-consistent emissions pricing extends the long-run shadow price of the binding emissions constraint, brings it forward in time and promotes shifts in relative prices economy-wide to reflect the future binding constraint. This is especially important in sectors that are expected to be relatively hard to decarbonize; it is less so but still important in sectors that are easy to decarbonize after allowing for dynamic impacts of industrial policies. Secondly, emissions pricing creates a market-based exit from industrial policies, helping to manage their policy costs and strengthen their efficiency. Thirdly, target-consistent emissions pricing differentiated across sectorsbetween relatively easy- and hard-to-decarbonize sectors - can help manage adverse distributional impacts of emissions pricing, especially on households. More targeted interventions to support adversely affected communities from structural changes, such as coal-mining communities and low-income households living in thermally inefficient dwellings, is also fundamental to managing effectively adverse distributional impacts of change. An early policy focus 
on energy and material efficiencies as warranted by market imperfections also create economic benefits that can help offset costs of other policies.

The institutional contexts for transforming energy systems, in addition, shape the effectiveness of reform strategies. For example, adapting government-designed energy markets and regulations to changing technologies is necessary for efficient investments in variable renewables like solar PV and wind turbines and complementary flexible-power technologies. Such adaptations are key to minimize overall, system-wide electricity costs. Moreover, economy-wide institutions to provide transparency of overall climate goals, reform strategies and their implementation promote greater public understanding of reforms and their goals and impacts. Such transparency promotes self-discipline in policy making and helps governments develop reputations for effective, goal-oriented reforms. Independent government advisory councils on climate are economy-wide examples of such institutions. Energy market monitoring agencies serve this role in government-designed and regulated electric power and natural gas markets.

But important as comprehensive, coherent and credible energy-reform strategies are for countries transforming their energy systems, each country acting in isolation would disappoint. Climate change is a global environmental externality, and all countries must act to achieve net zero emissions if the climate is to be stabilized. Moreover, country capabilities and interests in low-carbon alternatives necessary to eliminate net emissions from energy vary widely. Some countries have comparative advantages and specializations in innovations and manufacturing. Examples of such production capabilities include mass manufacturing of potential general-purpose technologies for low-carbon energy systems, such as solar PV panels and lithium-ion battery packs, as well as more complex technologies such as wind turbines. These countries have stronger interests in the development and early deployment of low-carbon technologies than others, and they are more likely to initiate industrial-policy-driven market disruptions of incumbent technologies. For them, innovations and low-carbon technology production are potential new sources of economic growth and international comparative advantage. At the same time, low-carbon technologies enable countries to derive value from heretofore largely untapped renewable resources such as solar irradiance and wind to produce modern energy. Many developing countries are abundantly endowed with these resources. Yet other countries have strong societal interests in limiting climate change with few reinforcing or opposing domestic economic interests. Many countries have abundant coal resources and use coal intensively for electric power generation and industrial production, with interests in maintaining the energy status quo. Most countries import crude oil and oil products; few are major oil exporters. 
These widely ranging domestic interests in the energy status quo, alternative low-carbon technologies and choices, renewable resource endowments and environmental protection shape international actions on climate change. The Nationally Determined Contributions (NDCs) of countries that signed the Paris Agreement - their climate action goals and plans - are representations of these varied interests at country level. The agreement's mechanism for peer review of NDCs create opportunities for countries to coordinate their climate actions and engage in more formal cooperation to advance their implementation. Such coordination can also arise outside the formal mechanisms of the Paris Agreement. In fact, there has been significant tacit coordination of - and some formal cooperation on-market-creating and industry-supporting policies for solar PV panels, wind turbines, lithium-ion battery packs and battery electric vehicles.

\section{THE LINE OF ARGUMENT}

Part I of the book sets out the societal, environmental and technological contexts for transforming modern energy systems.

Chapter 1 begins with a brief history of energy capture - the human capability to harness vast primary energy resources and use them well - and the emergence of modern societies through two industrial revolutions enabled by accumulating scientific and engineering knowledge. They transformed societies and lifted living standards to unprecedented heights. Almost all firms and households in advanced industrialized countries and many in developing ones now depend on modern energy supplies derived primarily from fossil resources for their economic and household activities. The two industrial revolutions and more recent innovations also provide valuable insights into market-based dynamics of energy-related technological change. For example, innovations that proved commercially successful emerged initially in countries with capacity for innovation and economic specializations in primary industries and manufacturing. The pace of initial market penetration is shaped by incumbent technology characteristics and those of alternatives. They then diffused widely across countries over time, with some acceleration.

Chapter 2 characterizes modern energy systems at the scale of individual firms and households, highlighting the interdependencies between their choices and those of state-owned and private firms that supply energy. It shows that energy is demanded for the useful services and materials that it enables. These benefits from energy flow through the energy-using equipment and appliances in buildings, transport vehicles and industrial processes for making useful materials like steel, cement, plastics and chemicals. The demand for energy is thus derived from the demand for other things. To transform energy systems, while maintaining living standards that benefit from current energy 
use and creating opportunities for sustainable growth, it is necessary to change technologies in much of the energy-using and energy-producing capital stock, including those for producing electric power and fuels. The chapter also explains why current technologies that use fossil fuels in traditional ways disrupt the Earth's carbon cycle and change its climate.

Energy systems must achieve net zero emissions of carbon dioxide if they are to stop putting pressure on the climate, and Chapter 3 begins with the climate science behind this requirement. Alternative energy end-use and supply technologies that could contribute to this outcome are then surveyed. The core of such systems is increasingly clear with recent advances in solar $\mathrm{PV}$, wind turbines and batteries. At their core would be electricity systems with zero or negative emissions and substantial generation shares from renewable resources, along with widespread electrification of economic activities. This core is now seen as relatively 'easy to decarbonize'. But other activities, especially in heavy industry and commercial transport, appear 'hard to decarbonize', needing low-carbon fuels such as hydrogen or carbon dioxide-removal technologies. While two decades ago most energy emissions then appeared hard to decarbonize, advancing low-carbon alternatives supported by innovation and industrial policies are expanding opportunities for change.

Part II recognizes that advances in low-carbon alternatives are endogenous developments in markets with multiple imperfections, have substantial risks and distributional impacts (positive and negative) and need comprehensive government policies to address and manage them (Stiglitz, 2019; Stern, 2021; and Stern and Stiglitz, 2021). It also recognizes the need to adapt market-supporting institutions for energy systems, including government-designed energy markets and regulations.

Chapter 4 begins by observing that the directions for technology advances in sectors now seen as easy to decarbonize took their lead from a series of oil price shocks and energy security concerns over several decades. It then examines evidence on market imperfections confronting low-carbon alternatives. Some are similar to those for new technologies in general, such as R\&D knowledge spillovers. Their more distinguishing features are external scale economies and network effects from deploying them in transforming energy systems. Such positive cost spillovers from early deployment of low-carbon alternatives are a key feature of ongoing transformations. Departing from the orthodoxy of using government supports for R\&D and emissions pricing alone to advance low-carbon alternatives, heterodox industrial policies were used to effectively address these and other market imperfections affecting their advance. This outcome is consistent with more general evidence on the effectiveness of industrial polices, especially when attuned to market competition.

While the need for pricing carbon dioxide emissions is clear, its calibration is not. Two concepts for emissions pricing are cost-effectiveness consistent 
with a quantitative emissions target and the social cost of carbon dioxide emissions. Chapter 5 examines their empirical foundations. They include the long-run marginal cost of abatement consistent with the target, recognizing that it subsumes some inherent uncertainties in the social-cost approach. Substantial inherent uncertainties in social costs and benefits drive a vast range of estimated social costs of carbon emissions, which is also examined. It is argued that a quantitative emissions target and cost-effective emissions pricing provide a more stable and informative focal point for government policies and long-run investment choices of businesses and households. Nevertheless, actual emissions pricing falls short of the levels and scope deemed adequate by either framing, though countries with more ambitious pricing benefit from low-carbon legacies such as hydroelectric and nuclear power.

Adapting energy markets, institutions and infrastructures to low-carbon alternatives is necessary to advance them, especially tailoring electricity markets' designs to variable renewables like solar PV and wind generation and complementary flexibility technologies for system balancing. Chapter 6 examines how electricity market designs balance controlling market power of generators in tight markets while ensuring electricity prices reflect the true scarcity value of electricity over time to remunerate system investments. Such scarcity pricing would also in principle need to remunerate upfront investments in advancing low-carbon power technologies in the absence of market-creating policies for them. Electricity market reforms such as capacity remuneration mechanisms aim to strike the market-design balance and ensure adequate investment in low-carbon generation capacity and flexibility. Natural gas infrastructures also need to adapt to low-carbon alternatives. A key challenge is coordination of investments in low-carbon alternatives in existing buildings, a task aided by upfront investments in building thermal efficiency.

Chapter 7 explores gaps between observed energy and material efficiencies and their feasible potentials. Gaps between actual and technically feasible energy efficiencies are relatively wide for buildings, household appliances and vehicles and narrow for heavy industries and commercial transport, although not all technically feasible efficiency gains are cost-effective. Evidence on causes of potential economic inefficiencies focuses on household investment decisions and energy choices regarding dwellings, appliances and automobiles. There is significant evidence that informational asymmetries, split incentives and behavioural anomalies contribute to economic inefficiencies. Evidence on energy efficiency policies finds that those that are well designed improve efficiency and overall welfare, including by directing innovations towards this somewhat neglected product characteristic. Similar issues arise for material efficiency, although available evidence is less extensive. Looking forward, efficiency policies should reflect expected shifts in relative prices arising from 
government climate goals and their implementing policies, especially those for building thermal and material efficiencies.

Part III explores the political economy of transforming energy systems, including domestic economic interests, societal and political values and institutions, and develops comprehensive domestic energy-reform strategies and approaches to their international coordination.

The political economy context for transforming energy systems is shaped by domestic economic interests, societal and political values, and institutions. While recognizing interests in the energy status quo, Chapter 8 focuses on interests in low-carbon alternatives and how they shape investments in knowledge and new capabilities necessary for low-carbon energy systems and implementation of policies that support them. Country capabilities and specializations in innovations and manufacturing are central to these foundational investments. Countries and firms that specialize in these activities are those that have largely initiated the technological disruptions to current energy systems, primarily by implementing market-creating and industry-supporting (industrial) policies. In addition, low-carbon technologies produce value from heretofore untapped renewable wind and solar resources, and many developing countries are relatively well endowed with them. They are potential sources of long-run economic growth and new comparative advantages for developing countries in a world with net zero emissions from energy.

Chapter 9, which concludes the book, distils from the preceding analysis and evidence key elements of energy-reform strategies. They are comprehensive in addressing market imperfections, risks and distributional impacts to advance and guide low-carbon alternatives to net zero emissions goals. They include industrial policies and emissions pricing consistent with these goals, appropriately sequenced and differentiated among easy- and hard-to-abate sectors. They also include adapting government-designed energy markets, regulations and infrastructures to low-carbon alternatives. Moreover, countries' comparative advantages and specializations in advancing low-carbon alternatives mean that acting in isolation would be costly and clearly fail to address the global environmental externality. The chapter concludes by exploring ways that countries, building on their domestic energy-reform strategies, can coordinate internationally climate actions and accelerate them towards achieving the Paris Agreement goals. While these approaches vary with technology characteristics and market structures, they point to the importance of sector-focused initiatives in accelerating change alongside countries' efforts. 